severe hypertension to tertiary referral centres. We do not recommend mass screening to detect children who may not have hypertension at later measurements and for whom there may be no benefits of detecting mild hypertension. Screening and long term follow up are indicated for children with renal diseases, neurofibromatosis, diabetes mellitus, and probably those with a family history of hypertension, however difficult this may be to define.

Senior Lecturer in Medicine,

M DE SWIET

National Heart and Lung Institute,

London SW3 6LY

Consultant Physician and Paediatric Nephrologist,

Hospital for Sick Children, London WC1N 3JH

1 Veterans Administration Cooperative Study Group on Antihypertensive Agents. A double blind control study of antihspertensive agents. Arch Intern. 11ed 1960;106:133-48.

M J DILLON
Swales JD, Ramsar LE, Coope JR, el al Treating mild hypertension. Br Mled f 1989-248.694-8.

De Swiet M, Favers P. Shinebourne EA. Blood pressure in 4 and 5 vear old children: the effects of environment and other factors in its measurement. The Brompton study. 7 Hypertens 1984;2: $501-5$.

+ Miall WE, Lovell HG. Relation between change of bleod pressure and age. Br.11ed f 1967;ii:660-4. De Swiet M, Fayers P, Shinebourne EA. The value of repeated blood pressure measurements in children - the Brompton study. Br.Med f 1980;280:1567-9.

6 Reader R, Baver GE, Dorle AE, et al. The Australian therapeutic trial in mild hypertension: report by the management committee. Lanct 1980;i:1261-7.

Biron P, Mongeau JG. Familial aggregation of blood pressure and its components. Pediatr Clin North Am 1978:25:29-33

8 Dillon MJ. Blood pressure. Arch Dis Child 1988;63:3+7-9.

9 Hall DMB, ed. Health for all children. A programme for child health surveillance. Oxford: Oxford University Press, 1989.25-6.

10 Voors AW, W'ehber LS, Frerichs RR, Berenson GS. Bodv height and bodv mass as determinants of basal blood pressure in children - the Bogalusa heart study. Am f Eipidemiol 1977;106:101-8.

1 Londe $S$. Cause of hyperion in the young Pediatr Clin North Am 1978:25.55-65.

12 Dillon MJ. Investigation and management of hypertension in children. A personal perspective. Pediatric Nephrology 1987;1:59-68.

3 Dillon MJ. Modern management of hypertension. In: Meadow R, ed. Recent advances in paediatrics. No 7. Edinburgh: Churchill Livingstone, 1984:35-55.

1t Rascher W, Bonzel ILE, Ruder H, Muller-Wiefel DE, Scharer K. Blood pressure and hormonal responses to sublingual nifedipine in acute childhood hypertension. Clin Exp Hypertens [A] $1986 ; 8: 859-69$

15 Portman RJ, Robson A.II. Controversies in paediatric hypertension. In: Tunes BM, Mendoza SA, eds. Pediatric nephrologv. New York: Churchill Livingstone, 1984:265-9.

\title{
The quality divide in primary care
}

\author{
Set to widen under the new contract
}

The evidence for a clear geographical divide in morbidity, mortality, and performance in primary care is consistent and indisputable. ${ }^{1-4}$ Yet it appears from the current debates over the new contract for general practice ${ }^{5}$ and the NHS review ${ }^{6}$ that there is still confusion about the underlying cause.

If disparities in, for example, rates for immunisation and cervical cytology are caused mainly by environmental factors $^{27-10}$ then social action (including subsidies for primary health care) is necessary. If, however, the root cause is the complacency, or even incompetence, of general practitioners in delivering care (failing to organise, computerise, or employ staff) then incentives and penalties are indicated. As the new arrangements in primary care seem to assume that complacency is the problem and that commitment ${ }^{11}$ and organisation ${ }^{12}$ in general practice may override social pressures, high quality evidence in this debate should be warmly welcomed.

In their book Family Doctors and Economic Incentives ${ }^{13}$ Bosanquet and Leese enlarge on previous publications ${ }^{1+15}$ to provide such evidence. The evidence is inevitably complex. They visited 260 practices in six areas of the country chosen for their socioeconomic diversity. These practices were scored on three markers-employing a practice nurse, vocational training, ${ }^{16}$ and using the cost rent scheme-and divided into innovators (two or three markers), intermediate (one marker), or traditional (no marker). Bosanquet and Leese looked for the characteristics, rewards, and penalties for these innovative practices.

The book provides ample evidence that the social milieu of the practice is the key predictor of performance: "Decisions on strategy seemed to be determined mainly by local environment rather than the personal characteristics of the doctors." 13 Practices in deprived areas had less income because of smaller lists (they were less likely to have a rising local population to allow funding through expansion) and fewer partners (and thus higher running costs for each partner). They were more likely to have Asian partners and were much less likely to innovate. Even within a predominantly affluent area such as the Thames valley the urban practices were not innovators. Practices in deprived areas thus have a substantially lower income than practices in more affluent areas and are, not surprisingly, therefore less likely to invest in their practices.
Low investment combined with falling populations leads to reduced income and even less likelihood of investment.

There is, however, also some support for the complacency argument. Regardless of social area the innovating practices are more likely to be larger partnerships, to have a partner who is a member of the Royal College of General Practitioners, and to hold separate baby, antenatal, and well person clinics. As innovating practices are more likely to be well equipped and well staffed this offers some pointers to the behaviour that the profession and the government might wish to encourage. We should remember, however, that larger practices may not always be popular with patients ${ }^{17}$ and that screening may unnecessarily medicalise the healthy. ${ }^{18}$

Although the new contract rewards holding clinics, it removes the group practice allowance. By concentrating substantial funds on attaining high targets it will differentially penalise the practices in deprived areas, and by altering the balance towards capitation fees it will further penalise those practices in areas of static or declining population. The only mitigation, the deprivation supplement to the basic practice allowance, was ill thought out in its original guise, and a new version is awaited. Unless its final form offers substantial rewards the disincentives to investment and innovation in practices in deprived areas will increase under the new contract.

If the Department of Health persists with its current strategy the incentives for vocational trainees to enter practice in socially deprived areas and for existing doctors in these areas to develop their care and services will decline. Rather than following the philosophy that "unto those that hath shall be given," rewards for achievement should relate to the magnitude of the task; otherwise the quality divide will only widen.

Senior Lecturer,

MIKE PRINGLE

Department of General Practice,

Nottingham University Medical School,

Nottingham NH7 2UH

1 Royal Commission on the National Health Service. Report. London: HMSO, 1979.

2 Department of Health and Social Security. Inequalities in health. London: DHSS, 1980. (Black report.

Jarman B. A survey of primary care in London. London: Royal College of General Practitioners, 1981. Occasional paper $\mathrm{No}_{0} 16$ 
+ London Health Planning Consortium, Primary Health Care Study Group. Primary health care in iner London. London: DHSS, 1981. Acheson report

Department of Health and Welsh Office. General practice in the National Health Service: a new comtract. London: Department of Health, 1989.

Secretaries of State for Health, Wales, Northern Ireland, and Scotland. Working for putients. London: HMSO, 1989. (Cmnd 555.)

Marsh (iN, Channing DM. Deprivation and health in one general practice. Br Med $f$ 1986;292:1173-6.

8 Jarman B. Underprivileged areas: validation and distribution of scores. $\mathrm{Br}$ Med $\mathcal{J}$ 1984;289. $1587-92$

9 Johnson IS, Milner PC. Is the Jarman score better than social class at assessing the need for prevention and primary care? Fam Pract 1988;5:105-10.

10 Smith C, Stiff J. Problems of inner city general practice in north-east London. $f R$ Coll (jen Pract 1985;35:71-6.
11 Marsh (iN, Channing DM. Narrowing the health gap between a deprived and an endowed community. Br.Med f 1988:296:173-6.

Rosedale M, Clark C, James J. Improved health care delivery in an inner-city well-baby clinic run hy general practitioners. $f R$ Coll (ien Pract 1986;36:512-3.

3 Bosanquer N Leese B. Family doctors and economic incentives. Aldershot: Dartmouth, 1989.

14 Bosanquet N, Leese B. Family doctors: their choice of practice strategy. Br Med F 1986;293 $667-70$.

15 Bosanquet N, Leese B. Family doctors and innovation in general practice, Br Med $\mathcal{F}$ 1988;296: 1576-80.

16 Baker R. Comparison of standards in training and non-training practices. $7 \mathrm{R}$ Coll Gen Pract 1985;35:330-2

17 Curtis SE. The patient's view of general practice in an urban area. Fum Pract 1987;4:200-6.

18 Williams ES, Barley NH. Old people not known to the general practitioner: low risk group. Br.Med f 1985;291:251-4.

\section{Disulfiram treatment for alcoholism}

\section{Deserves re-examination}

Over the past decade in Britain there has been a "demedicalisation" of the response to alcohol problems. The disease concept of alcoholism has been heavily criticised, cognitive and behavioural methods for modifying drinking behaviour have been increasingly used, and there has been a growing influence in the treatment and counselling of problem drinkers by professions other than medicine. All this may be the major reason why treatment with disulfiram has become generally unpopular. It is seen as drug treatment associated with an outmoded "medical model" of alcoholism. But fashions in treating alcoholism often bear little relation to research evidence. In Britain Brewer in particular has argued the case for disulfiram, ${ }^{1}$ and these arguments deserve objective appraisal.

According to Fuller and his colleagues, disulfiram is normally used in clinical practice in combination with alcoholism counselling and given to patients to take at home. ${ }^{2}$ This procedure formed the basis for two of the best designed trials of treating alcoholism. ${ }^{23}$ A first study showed that patients instructed to take either a standard regimen or a pharmacologically inactive dose of disulfiram took longer to relapse than those in a control group given riboflavin. ${ }^{3+}$ (Patients were blind to which disulfiram group they were in, which suggests that it is the deterrent effect of disulfiram rather than its pharmacological effect that is important.) This finding was not replicated in a large, multicentre trial using the same design. ${ }^{2}$ But in this trial older, more socially stable patients instructed to take the standard dose of disulfiram reported significantly fewer drinking days in the follow up period than those in control conditions. These results are unimportant only if one believes that the sole objective in treating alcoholism is total abstinence; to those who are primarily interested in reducing harm the results are of much greater interest. ${ }^{5}$

Despite the focus of the research by Fuller and others on the "unsupervised" use of disulfiram it has long been clear that compliance is the outstanding problem with disulfiram treatment, and since the early 1970 s there have been attempts to find ways of increasing compliance. Surgical implants were tried" but have been largely abandoned because of evidence of a lack of pharmacological and clinical effect. ${ }^{78} \mathrm{~A}$ more successful method depends on providing reinforcement or punishment contingent on whether or not the drug is taken. Punishments include loss of a financial security deposit," termination of clinic services, ${ }^{10}$ or reinstatement of suspended jail sentences among habitual drunk offenders. ${ }^{11-13}$ An example of reinforcement was to provide access to methadone for patients dependent on both heroin and alcohol. ${ }^{1+}$ These efforts are helped by improvements in assessing compliance by testing for metabolic products of disulfiram-that is, urinary diethylamine ${ }^{1516}$ and exhaled carbon disulphide..$^{17} 18$ When patients know that compliance is being monitored it tends to increase. ${ }^{19}$

It is, however, the simple principle of "supervised" use of disulfiram that is of major interest. Supervision may be by doctors, probation officers, or the patient's close relatives and may be on an informal basis or accompanied by a formal "behavioural contract" setting out mutual rights and obligations between the patient and the supervisor. ${ }^{2021}$ Using a form of contract Azrin and others found that for male alcoholic outpatients disulfiram use supervised by wives was significantly superior to unsupervised use. ${ }^{22}$ For single patients the addition of behaviour therapy resulted in an improved outcome, but for married patients supervised disulfiram alone gave optimal abstinence rates in the month before follow up.

Disulfiram with "enforced" compliance has also proved useful in treating recalcitrant; groups of alcoholics, such as concurrent heroin addicts ${ }^{1+}$ and repeated drunk offenders. ${ }^{12} 13$ Much of this evidence relies on using patients as their own controls - that is, showing a much improved outcome after treatment among those with poor adjustment and treatment failures in the past. What is needed is a large, properly designed treatment trial comparing supervised with unsupervised use of disulfiram. We also need more information on its use with women and other groups. But even without this evidence doctors and researchers should pay more attention to treatment with supervised disulfiram because treatments of proved effectiveness are few and desperately needed.

Perhaps psychologists and others might take a more open attitude to disulfiram if they realised that it is in fact a behavioural treatment; its only strictly "medical" aspect is that it requires a medical qualification to prescribe and monitor its use. Disulfiram works mainly by altering the possibilities for reinforcement that apply to drinking - that is, by replacing delayed with immediate negative consequences. This leaves open the question of what happens when the new contingencies are no longer in force-in other words, when the patient eventually stops taking the drug. Brewer has suggested that disulfiram entails a naturalistic form of "cue exposure with response prevention"-that is, where the patient is exposed to circumstances with a high risk for relapse while the response of drinking is prevented-similar to that used for obsessive-compulsive and phobic patients, thus introducing the possibility of more lasting benefits. ${ }^{23}$ This interesting suggestion should be researched. At the least, successful disulfiram treatment provides the patient with a respite from the ravages of heavy drinking and a break in the vicious circle of mounting personal and social problems 